\title{
Mesophotic coral ecosystems on the walls of Coral Sea atolls
}

Received: 2 December 2010/ Accepted: 12 January 2011 / Published online: 30 January 2011

(C) Springer-Verlag 2011
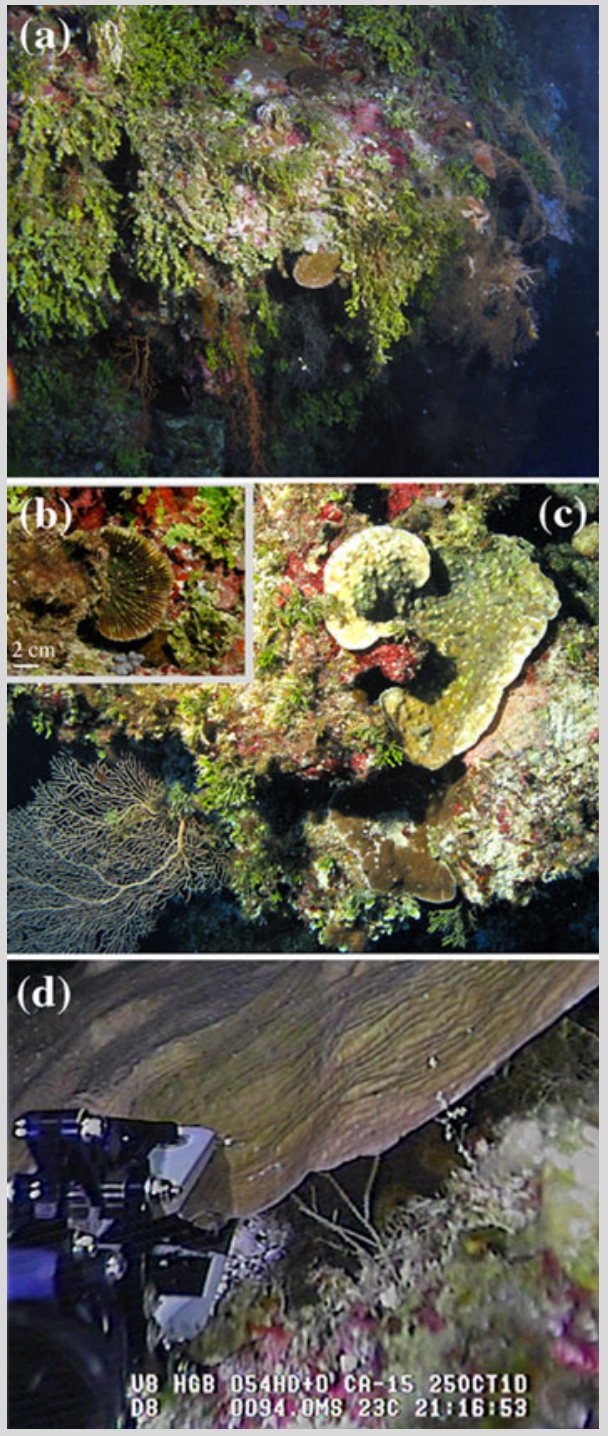

Fig. 1 a Halimeda curtains at $50 \mathrm{~m}$, b Echinomorpha nishihirai at $40 \mathrm{~m}$, c Mycedium elephantotus at $40 \mathrm{~m}$, d ROV collecting from a large Pachyseris speciosa colony at $94 \mathrm{~m}$
A research cruise was undertaken in October 2010 to explore potential mesophotic coral communities $(30-150 \mathrm{~m})$ in the recently established Coral Sea Conservation Zone (CSCZ). The CSCZ covers an area of almost one million square kilometres east of the Great Barrier Reef (Australia), with its reefs and atolls located hundreds of kilometres from the nearest landmass and surrounded by deep oceanic water. Three of the atolls in the CSCZ (West Holmes Reef $\left[16.243^{\circ} \mathrm{S}, 147.874^{\circ} \mathrm{E}\right]$, East Holmes Reef $\left[16.459^{\circ} \mathrm{S}\right.$, $\left.148.024^{\circ} \mathrm{E}\right]$ and Flora Reef $\left.\left[16.755^{\circ} \mathrm{S}, 147.738^{\circ} \mathrm{E}\right]\right)$ were assessed using SCUBA and a Seabotix ROV. Shallow reef areas $(<30 \mathrm{~m})$ consisted largely of bare substrate with predominantly juvenile corals and very low coral cover due to past cyclone damage and thermal bleaching events. In contrast, the steep walls in $40-100 \mathrm{~m}$ depth were covered by extensive Halimeda curtains (Fig. 1a), which harboured diverse scleractinian coral communities, including Acropora, Astreopora, Fungia, Galaxea, Goniastrea, Porites, Mycedium (Fig. 1c), Seriatopora and Turbinaria spp., with Pachyseris (Fig. 1d), Leptoseris and Montipora spp. recorded to $102 \mathrm{~m}$ depth. At least one of the collected specimens represents a new species record for Australia: Echinomorpha nishihirai (Fig. 1b). Diverse communities of azooxanthellate octocorals were also observed to $150 \mathrm{~m}$, the maximum depth of the ROV. These observations confirm the presence of mesophotic coral ecosystems (MCEs) along the walls of Coral Sea atolls and indicate that MCEs may form extensive features in the CSCZ. The deep-water coral communities may play an important role in the recovery of shallow reef areas on these isolated atolls by functioning as refugia from the repeated disturbances that have affected these reefs.

Acknowledgments The authors thank David Whillas, B. Greg Mitchell, Michel Pichon, Jody Webster, Iain Faichney, Oscar Pizarro, Ed Roberts and Eye to Eye Marine Encounters for their assistance and acknowledge Australian Geographic, C\&R Consulting, the National Science Foundation (ATM-0941760) and the Pacific Blue Foundation for funding.

P. Bongaerts and T. C. L. Bridge have contributed equally to this article.

P. Bongaerts $(\bowtie) \cdot$ D. I. Kline $\cdot$ O. Hoegh-Guldberg

Global Change Institute, The University of Queensland, St Lucia, QLD 4072, Australia

e-mail: pim@uq.edu.au

T. C. L. Bridge

School of Earth and Environmental Sciences, James Cook University, Townsville, QLD 4811, Australia

P. R. Muir · C. C. Wallace

Museum of Tropical Queensland, Townsville, QLD 4810, Australia

R. J. Beaman

School of Earth and Environmental Sciences, James Cook University, Cairns, QLD 4870, Australia 